\title{
DEFYING THE CHANGES OF LEXICAL MEANING IN THE ASSOCIATIVE EXPERIMENT (ON THE EXAMPLE OF LEXEME DELO)
}

\author{
Anna I. Khlopova \\ Moscow State Linguistic University, Moscow, Russia
}

\begin{abstract}
The article is devoted to revealing the dynamics of the meaning of the lexeme delo for the last 30 years. To achieve this goal, the author carries out a complex analysis of the lexeme on the material of the Russian dictionaries: definition analysis, component analysis, analysis of the Russian Associative Dictionary (RAD) and their comparison with the data of the associative experiment. It has been established that the conceptual content of the lexeme is business-proof, since the reactions of the RAD respondents and the values of the lexical unit in modern semes, that are part of the core semantic structure of the word delo modeled on the basis of a definitional analysis, coincide in the reactions of the respondents obtained in the course of the associative experiment. The idea of Yu.N. Karaulov that the importance of lexemes remains unchanged among respondents for 2-3 generations has been proved. Changes in the lexical meaning of the word delo, revealed when comparing the dictionary data and the results of the experiment, are viewed as the relevance of the periphery of the sememes and the values of the lexeme associated with them. The conducted research confirmed the expediency of using the experimental method in studying language processes in their connection with the thinking of native speakers.

Key words: lexeme, lexical meaning, dynamics of lexical meaning, semantic structure, free associative experiment.

Citation. Khlopova A.I. Defying the Changes of Lexical Meaning in the Associative Experiment (on the Example of Lexeme 'Delo'). Vestnik Volgogradskogo gosudarstvennogo universiteta. Seriya 2, Yazykoznanie [Science Journal of Volgograd State University. Linguistics], 2018, vol. 17, no. 2, pp. 82-89. (in Russian). DOI: https://doi.org/10.15688/jvolsu2.2018.2.9
\end{abstract}

\section{ИЗМЕНЕНИЯ В ЛЕКСИЧЕСКОМ ЗНАЧЕНИИ СЛОВА ДЕЛО (ПО ДАННЫМ АССОЦИАТИВНОГО ЭКСПЕРИМЕНТА)}

\author{
Анна Игоревна Хлопова \\ Московский государственный лингвистический университет, г. Москва, Россия
}

\begin{abstract}
Аннотация. Статья посвящена выявлению динамики значения лексемы дело за последние 30 лет. С этой целью осуществлен комплексный анализ лексемы на основе материала словарей русского языка: дефиниционный анализ, компонентный анализ, анализ данных «Русского ассоциативного словаря» и их сравнение с данными, полученными в ходе проведенного автором ассоциативного эксперимента.

Установлено, что понятийное содержание лексемы дело устойчиво, поскольку реакции респондентов РАС и значения рассматриваемой лексической единицы в современных словарях в основном совпадают; семы, входящие в ядро семантической структуры слова дело, смоделированной на основе дефиниционного анализа, находят отражение в реакциях респондентов, полученных в ходе ассоциативного эксперимента. Подтверждена идея Ю.Н. Караулова о том, что значение лексем остается неизменным у респондентов в течение 2-3 поколений. Изменения лексического значения слова дело, выявленные при сопоставлении словарных данных и результатов проведенного эксперимента, выражаются в утрате актуальности периферий() ными семами и связанными с ними значениями исследуемой лексемы.
\end{abstract}


Проведенное исследование подтвердило целесообразность использования экпериментального метода при изучении языковых процессов в их связи с мышлением носителей языка.

Ключевые слова: лексема, лексическое значение, динамика лексического значения, семантическая структура, свободный ассоциативный эксперимент.

Цитирование. Хлопова А. И. Изменения в лексическом значении слова дело (по данным ассоциативного эксперимента) // Вестник Волгоградского государственного университета. Серия 2, Языкознание. - 2018. T. 17, № 2. - C. 82-89. - DOI: https://doi.org/10.15688/jvolsu2.2018.2.9

\section{Введение}

Исследователи отмечают, что в современных науках (психологии, лингвистике, психиатрии) свободный ассоциативный эксперимент (далее - АЭ) стал использоваться для решения разнообразных теоретических и практических задач, поскольку он относительно прост в проведении (но не в обработке результатов!), а его данные высоко информативны [Караулов, 1981, с. 150]. Если раньше АЭ применялся в лингвистических исследованиях для моделирования статичных семантических структур, то в современной лингвистике, решая на основе интерпретации ассоциативных полей лингвокогнитивные, лингвокультурологические и психолингвистические задачи, ученые обнаружили внутреннюю пластичность ассоциатов. Это позволило в полном соответствии с антропоцентрическим подходом использовать их для интерпретации динамики языковых процессов. АЭ становится эффективным способом изучения развития лексических значений, хотя далеко не весь его потенциал выявлен [Патсис, 2005, с. 11]. Сопоставляя структуру ассоциативных полей определенных словстимулов, можно получить представление о том, каково психологически актуальное значение лексем для носителей языка и как оно изменяется в речевой деятельности социума. Более того, по мнению А.А. Залевской, изучая семантическую структуру слов-коррелятов в ряде языков, можно установить не только их лексико-семантические варианты, но и степень актуальности каждого варианта для носителей того или иного языка [Залевская, 2012, с. 31]. Значения слов, отраженные в словарях, изменяются: устаревают, исчезают, вместо них появляются новые. Данные свободного АЭ могут продуктивно использоваться при сопоставительном анализе для определения ядерных компонентов значения слова, актуальных для носителей исследуемого языка.

\section{Методика исследования}

Использование нескольких методов исследования обеспечивает надежность и достоверность сделанных выводов [Пищальникова, 2007, с. 117]. С целью определения динамики лексического значения слова дело мы провели его дефиниционный и компонентный анализ на основе данных, представленных в словарях русского языка, дополнили полученные результаты данными РАС и сопоставили их с данными проведенного нами ассоциативного эксперимента.

\section{Структура значения лексемы дело по данным словарей русского языка}

На первом этапе анализа лексемы дело с опорой на дефиниции из толковых словарей русского языка (см. список словарей) на основе компонентного анализа устанавливаем ядерные и периферийные семы. К ядерным относим семы, отражающие существенные (понятийные) признаки и потому актуализирующиеся во всех словарных дефинициях: 'работа', 'деятельность', 'занятие', 'деловая надобность', 'потребность, нужда', 'нечто важное, нужное', 'круг знаний', 'событие, происшествие, факт', 'поступок', 'судебный процесс', 'документы', 'обязанность', 'профессия', 'долг'. Остальные семы, представленные в дефинициях непоследовательно, относим к периферийным: 'заинтересованность, заботливое отношение'; 'все, что входит в какую-л. задачу, относится к какому-л. явлению'; 'полезное занятие'; 'сражение, бой (воен.)'.

Опираясь на синонимический ряд слова дело (СРС), выделяем семы, отсутствующие в дефинициях из толковых словарей: 'ремесло', 'мастерство', 'рукоделие', 'труд’, 'спор', 'произведение', 'сделка'.

Сопоставляя полученные результаты, определяем в качестве ядерных в структуре 


\section{РАЗВИТИЕ И ФУНКЦИОНИРОВАНИЕ РУССКОГО ЯЗЫКА}

значения слова дело семы 'работа', 'занятие', 'деятельность', 'суд', 'процесс', 'профессия'.

Такой предваряющий анализ необходим для того, чтобы, опираясь на экспериментальные данные, показать динамику значения исследуемой лексемы. Он является своеобразной «точкой отсчета» для характеристики актуальных психологических процессов, влияющих на развитие лексического значения и обнаруживающихся в свободном ассоциативном эксперименте.

\section{Значения лексемы дело по данным «Русского ассоциативного словаря»}

Для характеристики изменений в структуре значения слова дело обратимся к РАС, представляющему ассоциаты на это слово в возрастной группе респондентов от 17 до 23 лет. Поскольку в исследовании экспериментальных данных осуществляется переход к иной, психолингвистической, парадигме отметим, что соотношение «стимул - ассоциат» рассматривается нами, вслед за А.А. Леонтьевым, как предикативное отношение, выявляющее психологически актуальные для индивида смыслы (субъективно актуальные в данной речевой деятельности значения) [Леонтьев, 2003, с. 165]. Поэтому новые ассоциативные связи слова-стимула отражают как развитие его сочетательных возможностей в индивидуальной речевой деятельности, а наличие общих тенденций в этом процессе может свидетельствовать о начавшемся или осуществляющемся в настоящее время изменении значения слова.

В РАС на слово-стимул дело представлено 87 реакций. Из них методом случайной выборки нами выделено 53 реакции (для релевантного сравнения): сделал 5, в шляпе, жизни, дрянь 2, мое, бизнес, время, делается, мокрое, папка, уголовное, 13, № 13, №, альманах со стихами Д.А. Пригова, было, было так, в жизнь, времени, всей жизни, грабеж, для мужчины, досье, закрытие, закрыто, Ильича, каждого, любимое, мастер, милиция, не твое, потребность, пошло веселее, прибыльное, работа, сделать, серьезно, случая, собственное, судебное, табак, тело, труд, хорошее, худо, чести 1 .
Классифицируем ассоциаты в соответствии со значениями слова дело, чтобы продемонстрировать их актуальность / неактуальность в индивидуальном ассоциировании (а следовательно, возможном использовании в речевой деятельности индивида).

Реакции, соответствующие значению «работа, занятие, деятельность»: бизнес, $p a-$ бота, труд, любимое, пошло веселее, делается, сделать, сделал 5, жизни 2, всей жизни, время, в жизнь (всего 17).

Реакции, соответствующие значению «событие, факт, положение вещей»: дрянь 2, в шляпе 2, худо, табак, было, случая, времени, пошло веселее, было так (всего 11).

Реакции, соответствующие значению «судебное разбирательство, процесс»: уголовное, альманах со стихами Д.А. Пригова, грабеж, закрытие, закрыто, судебное, чести (всего 7).

Реакции, соответствующие значению «собрание документов, относящихся к какому-л. лицу»: папка, досье, № 13, 3, № (всего 5).

Реакции, соответствующие значению «то, что входит в чьи-нибудь задачи»: не твое, мое, Ильича, каждого (всего 4).

Реакции, соответствующие значению «поступок»: для мужчины, хорошее, мокрое (всего 3).

Реакции, соответствующие значению «сфера знаний, деятельности, работы»: милиици, мастер (всего 2).

Реакции, соответствующие значению «предприятие»: прибыльное, собственное (всего 2).

Реакции, соответствующие значению «надобность, нужда»: потребность (всего 1).

Реакции, соответствующие значению «нечто важное, нужное»: серьезно (всего 1).

Большинство реакций, представленных в PAC, отражают ядерные семы 'работа', 'занятие', 'деятельность'.

Чтобы акцентировать динамические процессы в значении исследуемого слова, классифицируем полученные ассоциаты в соответствии с предложенной В.А. Пищальниковой моделью ассоциативного значения [Пищальникова, 2007, с. 154] и проинтерпретируем их. Модель ассоциативного значения включает в себя «принципиально функциональное, динамическое соотношение» следующих компонен- 
тов: понятие, представление, предметное содержание, ассоциация, операциональные реакции, которые в свою очередь могут отображать культурно обусловленные смыслы и эмоционально-оценочные связи единиц языка. [Пищальникова, 2007, с. 154]. Названная психолингвистическая модель избирается нами потому, что она представляет личностный смысл как функциональный феномен и позволяет проследить смысловые сдвиги значения в каждом конкретном предикативном отношении лексем, в нашем случае - в соотношении стимула и реакции.

Выделим прежде всего операциональные реакции, в которых отражается автоматизм использования лексем, что свидетельствует об их встроенности в ассоциативновербальную сеть индивидов: сделал 5, дрянь 2, жизни 2, пошло веселее, не твое, было, случая, времени, уголовное, судебное, закрытие, закрыто, мокрое, делается, сделать, любимое, серьезно, худо, табак, хорошее, в шляпе, всей жизни, время, в жизнь, мое, Ильича, каждого, мастер, было так, чести (всего 36). В составе операциональных ассоциатов можно выделить культурно обусловленные и эмоционально-оценочные. Значительна группа реакций-представлений: бизнес, собственное, потребность, милииия, альманах со стихами Д.А. Пригова, грабеж, для мужчины, папка, к другу, доcьe, № 13, 3, № (всего 14). Реакции-понятия, отражающие ядерные (понятийные) семы лексемы дело, представлены незначительно: работа, труд, прибыльное (всего 3).

Формальные фонетические реакции, как правило, не частотны, поскольку они отражают не значение, а степень знания его индивидом или актуальность для данной речевой деятельности, в нашем материале они представлены одним ассоциатом: тело.

Преобладание операциональных ассоциатов свидетельствует о том, что исследуемая лексема активно используется в речевой деятельности индивидов, фиксируя устойчивые составляющие ее значения, вербализованные в устойчивых сочетательных связях слова. Например, со значением слова дело «судебное разбирательство, процесс» связаны реакции закрытие и закрыто.
Среди операциональных реакций наиболее частотны в ассоциативном поле слова дело культурно обусловленные реакции: сделал, в шляпе, жизни, дрянь и др. Они актуализируют содержание устойчивых словосочетаний.

Реакция было реализует связь стимула с выражением было дело в значении подтверждения реальности факта или события. Ассоциат было так является традиционным началом текстов сказочно-былинных жанров. Реакции было и было дело актуализируют значение слова дело как «событие, обстоятельство, факт; положение вещей». Выражение дело случая понимается как «игра случая, игра судьбы, ирония судьбы, случай, нечаянность, лотерея, случайность».

Реакция сделал связана с поговоркой сделал дело, гуляй смело.

Фразеологизм дело в шляпе означает, что все хорошо, все в порядке, говорит об успешном завершении, исходе чего-либо. Несколько столетий назад, когда почты в современном ее виде не существовало, все сообщения доставлялись гонцами на лошадях. На проезжих дорогах тогда было немало разбойников, и сумка с пакетом могла привлечь внимание грабителей. Поэтому важные бумаги, или, как их раньше называли, дела, зашивали под подкладку шляпы или шапки. Отсюда возникло выражение дело в шляпе.

Выражение дело табак заимствовано в разговорную речь из жаргона волжских бурлаков. Переходя вброд неглубокие заливы или небольшие притоки Волги, бурлаки подвязывали свои кисеты с табаком к шее, чтобы они не намокали. Когда вода была настолько высока, что подходила к шее и табак намокал, бурлаки считали переход невозможным, а свое положение в этих случаях очень плохим, безнадежным. Сейчас это выражение употребляется в значении «очень плохо, безнадежно».

Наряду с ними слова-реакции представляют и иные устойчивые словосочетания. Так, реакция делается может быть связана с поговоркой скоро сказка сказывается, да не скоро дело делается и разговорным дело делается. Она означает, что какое-либо событие, дело, действие, процесс проходит гораздо медленнее, чем хотелось бы. Ассоциат дрянь актуализирует содержание фразеоло- 


\section{РАЗВИТИЕ И ФУНКЦИОНИРОВАНИЕ РУССКОГО ЯЗЫКА}

гизма дело дрянь, который означает, что дела очень плохи, положение крайне опасно, угрожающе. Жаргонное название убийства - мокрое дело - является распространенным в современной речевой практике социума. Ассоциат времени связан с поговоркой Делу - время, потехе - час. Реакция мастер актуализирует, вероятно, содержание поговорки Дело мастера боится, хотя не исключаются и другие интерпретации в связи со спецификой социально-исторических процессов в то время, когда проводился эксперимент для создания РАС. Так, «Толковый словарь языка Совдепии» (далее - ТСЯС) представляет устойчивое сочетание заплечных дел мастер, которое метафорически трактуется как «агент центрального разведывательного управления США»: Американские специалисты по антиповстанческим операчиям, «заплечных дел мастера», а также эксперты по подрывной деятельности в странах Карибского бассейна празднуют новоселье (ТСЯС, с. 152).

Реакции жизнь и в жизнь опосредованно связаны, вероятно, со штампом воплотить в жизнь, а ассоциаты жизни и всей жизни с устойчивыми социально-политическими штампами дело всей жизни, дело жизни. К этой же группе ассоциатов, фиксирующих социально-политические штампы, можно отнести чести, актуализирующее дело чести; Ильича - дело Ильича и др. Большое количество ассоциатов, представляющих те или иные связи с социально-политическими штампами, говорит об активности последних в речи в 80-е годы.

Ассоциат мое дело входит в ряд экспрессивных разговорных устойчивых словосочетаний с диффузной семантикой, активно используемых в рамках русской лингвокультуры: (это) мое дело, (это) не твое дело, (это) дело каждого, дело твое (его, ваше).

Анализируя эмоционально-оценочные реакции, отметим, что количество отрицательных и положительных оценок слова примерно одинаково (5 отрицательных и 4 положительные реакции). Можно полагать, что для респондентов слово дело эмоционально.

Частотность реакций-представлений также свидетельствует о включенности значения лексемы в систему индивидуальных ассоциативных связей, фиксирующих лично- стное отношение к реалии, обозначенной словом. При этом ассоциативные связи могут быть непрямыми. Например, реакция альманах со стихами Д.А. Пригова связана с именем Дмитрия Александровича Пригова - русского поэта, художника, скульптора XX в., одного из основоположников московского концептуализма в искусстве и литературе. Возможно, реакция дело обусловлена тем, что в 1986 г. после одного из уличных выступлений на Д.А. Пригова было заведено уголовное дело, он был принудительно направлен на лечение в психиатрическую клинику, откуда его освободили благодаря вмешательству известных деятелей культуры внутри и вне страны.

Реакция потребность отражает существующую в сознании носителей языка связь дела и внутреннего психологического или функционального ощущения недостаточности чеголибо, которое побуждает человека к деятельности. Таким образом, реакция потребность опосредованно актуализирует одно из значений слова дело - «надобность, нужда».

Содержание частотных реакций, выявленное в результате анализа данных РАС, позволяет определить общие значения слова дело для РАС и толковых словарей: «работа, занятие, деятельность»; «событие, обстоятельство, факт; положение вещей»; «судебное разбирательство, процесс»; первое и третье из них отражают ядерные семы 'работа', 'занятие', 'суд’, 'процесс', ‘профессия', 'деятельность', установленные при дефиниционном анализе лексемы.

\section{Значения лексемы дело по данным ассоциативного эксперимента}

В проведенном нами в 2014 г. ассоциативном эксперименте приняли участие 530 носителей русского языка 17-23 лет, поскольку, по мнению Ю.Н. Караулова, к этому возрасту завершается становление «языковой личности», «в ассоциациях находит отражение сформировавшаяся языковая способность участника эксперимента» [Караулов, 1981, с. 230]. Ю.Н. Караулов полагает, что «относительная стабильность языковой способности носителей языка (в частности словарный запас, ценностные и прагматические установки, формально-комбинаторные возможности) может 
служить основой для характеристики массового сознания в российском обществе на ближайшие 20-30 лет, т. е. на период, когда нынешние испытуемые будут составлять активное ядро общества» [Караулов, 1981, с. 231]. Испытуемые этой группы (большинство из них студенты) имеют приблизительно одинаковые интересы, проживают с родителями или зависят от них материально и не имеют постоянной работы. Поэтому можно предположить, что базовые ценности респондентов этой группы сопоставимы.

Из общего количества реакций методом случайных чисел мы отобрали 53 реакции: время 4, важное 4, бумага 3, работа 3, занятость 2, труд 2, задание 2, любимое 2, занятие, кепка, милиция, шум, хорошее, долг, удовлетворение, производство, безделье, деятельность, активность, папка, карьера, стирка, действие, секрет, ответственность, выполнение, жизнь, сделано, уголовное, трудное, легкое, личное; отказ от ассоциирования (7). (Последний показатель важен для количественного анализа составляющих ассоциативного поля).

Классифицируем реакции в соответствии со значениями слова дело и интерпретируем их.

Реакции, соответствующие значению «работа, занятие, деятельность»: работа 3 , занятость, труд, любимое 2, ответственность, выполнение, деятельность, активность, занятие, действие, удовлетворение, трудное, легкое, хорошее, безделье, сделано, время (всего 22).

Реакции, соответствующие значению «собрание документов, относящихся к какому-л. лицу»: бумага 3, папка, секрет, личное (всего 6).

Реакции, соответствующиезначению «то, что входит в чьи-нибудь задачи»: задание 2 , кепка, стирка, секрет (всего 5).

Реакции, соответствующие значению «нечто важное, нужное»: важное 4, шум (всего 5).

Реакции, соответствующие значению «сфера знаний, деятельности, работы»: милиция, жизнь (всего 2).

Реакции, соответствующие значению «предприятие»: карьера, производство (всего 2).

Реакции, соответствующие значению «надобность, нужда»: долг (всего 1).
Реакции, соответствующие значению «судебное разбирательство, процесс»: уголовное (всего 1).

Реакции, соответствующие значению «событие, факт, положение вещей» - 0 .

Реакции, соответствующие значению «поступок» -0.

Большинство реакций, данных респондентами, отражают, как и реакции, представленные в РАС, значение «работа, занятие, деятельность» и ядерные семы 'работа', 'занятие', 'деятельность'. Значения «событие, факт, положение вещей» и значение «поступок», зафиксированные в РАС, не отражены в реакциях наших респондентов. Следовательно, можно предположить, что содержание лексемы частично меняется: если некоторые значения сохраняются («работа, занятие, деятельность», «собрание документов, относящихся к какому-либо лицу») и не теряют своей актуальности, то другие становятся малоупотребительными или не используются.

Классифицируем ассоциаты, полученные в результате эксперимента, в соответствии с избранной моделью значения.

Реакции-понятия: работа 3 , труд 2 , занятость 2, задание 2, занятие, действие, производство, ответственность, выполнение, деятельность, активность, долг, уголовное 1 (всего 18).

Операциональные реакции: важное 4, время 4, любимое 2, безделье, личное, сделано, удовлетворение, трудное, легкое, хоромее 1 (всего 17).

В составе операциональных ассоциатов можно выделить культурно обусловленные (время, личное, сделано) и эмоционально-оценочные (важное, любимое, безделье, удовлетворение, трудное, легкое, хорошее).

Реакции-представления: бумага 3 , кеп$\kappa a$, стирка, секрет, карьера, жизнь, милииия, шум, папка 1 (всего 11).

Таким образом, значениями слова дело, зафиксированными в словарях русского языка и представленными в реакциях респондентов, являются: «работа, занятие, деятельность», «собрание документов, относящихся к какому-либо лицу»; «нечто важное, нужное», которые отражают семы 'работа', 'докумен- 


\section{РАЗВИТИЕ И ФУНКЦИОНИРОВАНИЕ РУССКОГО ЯЗЫКА}

ты', ‘важное', выявленные при дефиниционном анализе лексемы.

\section{Выводы}

Сопоставление результатов анализа данных, представленных в РАС и полученных в ходе проведенного нами свободного ассоциативного эксперимента, выявило следующие расхождения.

Различается состав наиболее частотных реакций на слово дело: если в РАС это были ассоциаты сделал, в шляпе, жизни, дрянь, то по данным эксперимента это время, важное, бумага, работа. Формально-грамматические ассоциаты единично представлены в РАС и отсутствуют среди реакций участников АЭ. Снижается степень индивидуальности реакций, что проявляется в утрате частотных культурных и эмоционально-оценочных реакций и актуализации понятийных ассоциатов. Кроме того, изменяется качественный состав эмоционально-оценочных реакций, значительно снижается их семантическая дифференцированность. Вместе с тем ядро значения слова дело, выявленное при анализе ассоциатов, частично совпадает с ядром значения, смоделированным при анализе словарных дефиниций: делоэто работа, занятие, деятельность, оно может быть судебным или уголовным.

Таким образом, можно считать, что понятийное содержание лексемы дело сохраняет устойчивость, и это, с одной стороны, подтверждает мнение Ю.Н. Караулова о неизменности значения лексем у респондентов в течение 2-3 поколений. С другой стороны, в эксперименте 2014 г. не проявляются как актуальные понятийные семы 'событие', 'факт', 'положение вещей', 'поступок', что свидетельствует об изменении значения анализируемой лексемы.

Динамика значения отражается также в изменении для респондентов актуальности ассоциативных связей с данным словом: в уменьшении (до нуля) количества формально-грамматических ассоциатов, в изменении степени субъективности реакций и их эмоционально-оценочного разнообразия, в утрате частотных культурных и эмоционально-оценочных реакций, в актуализации понятийных ассоциатов.

\section{СПИСОК ЛИТЕРАТУРЫ}

Залевская А. А., 2012. Двойная жизнь значения слова и возможности ее исследования: теоретическое и экспериментальное исследование. Saarbrücken : Palmarium Academic Publishing. $278 \mathrm{c}$.

Караулов Ю. Н., 1981. Лингвистическое конструирование и тезаурус литературного языка. М. : Наука. 367 c.

Леонтьев А. А., 2003. Психолингвистические единицы и порождение речевого высказывания. М. : Едиториал УРСС. 248 с.

Патсис М., 2005. Ассоциативное поле как инструмент анализа значения слова (на материале греческого языка) : дис. ... канд. филол. наук. M. $167 \mathrm{c}$.

Пищальникова В. А., 2007. История и теория психолингвистики : в 3 ч. Ч. 2. Этнопсихолингвистика. М. : Моск. гос. лингв. ун-т. 227 с.

\section{СЛОВАРИ}

Абрамов Н. Словарь русских синонимов и сходных по смыслу выражений. URL: http://slovari.ru/ default.aspx? $\mathrm{p}=237$.

Ефремова Т. Ф. Толковый словарь русского языка. URL: http://mirslovarei.com/efr_a (дата обращения: 15.04.2017).

$P A C$ - Русский ассоциативный словарь / под ред. Ю. Н. Караулова. URL: http://tesaurus.ru/dict/ dict.php (дата обращения: 29.03.2017).

Толковый словарь русского языка. URL: http://www. ozhegov.org/ (дата обращения: 12.05.2017).

Толковый словарь русского языка / под ред. Д. Н. Ушакова. URL: http://ushakovdictionary. $\mathrm{ru} /$ (дата обращения: 12.05.2017).

TCЯС-Мокиенко В. М., Никитина Т. Г., 1998. Толковый словарь языка Совдепии. СПб. : Фолиопресс. 704 с.

\section{REFERENCES}

Zalevskaya A.A., 2012. Dual life of the word's meaning and the possibilities of its investigation: theoretical and experimental research. Saarbrücken, Palmarium Academic Publishing. 278 p.

Karaulov Yu.N., 1981. Linguistic construction and thesaurus of the literary language. Moscow, Nauka Publ. 367 p.

Leontyev A.A., 2003. Psycholinguistic units and the production of speech utterances. Moscow, Editorial URSS. $248 \mathrm{p}$. 
А.И. Хлопова. Изменения в лексическом значении слова дело (по данным ассоциативного эксперимента)

Patsis M., 2005. Associative field as a tool for analyzing the word's meaning (on the material of the Greek language). PhD Thesis. Moscow. $167 \mathrm{p}$.

Pishchalnikova V.A., 2007. History and theory of psycholinguistics. In 3 parts. Part 2. Ethnopsycholinguistics. Moscow, Izd-vo MGLU. $227 \mathrm{p}$.

\section{DICTIONARIES}

Abramov N. Dictionary of Russian synonyms and similar expressions. URL: http://slovari.ru/ default.aspx? $\mathrm{p}=237$.
Efremova T.F. Explanatory dictionary of the Russian language. URL: http://mirslovarei.com/efr_a. (accessed 15 April 2017).

Karaulov Yu.N., ed. Russian dictionary of associations. URL: http://www.tesaurus.ru/dict/dict.php/. (accessed 29 March 2017).

Explanatory dictionary of the Russian language. URL: http://www.ozhegov.org/. (accessed 12 May 2017).

Ushakov D.N., ed. Explanatory dictionary of the Russian language. URL: http://ushakovdictionary.ru/. (accessed 12 May 2017).

Mokienko V.M., Nikitina T.G., 1998. Explanatory dictionary of the Soviet language. Saint Petersburg, Folio Press, 704 p.

\section{Information about the Author}

Anna I. Khlopova, Postgraduate Student, Department of General and Comparative Linguistics, Moscow State Linguistic University, Ostozhenka St., 38/1, 119034 Moscow, Russia, chlopova_anna@mail.ru, https://orcid.org/0000-0002-6576-4111

\section{Информация об авторе}

Анна Игоревна Хлопова, аспирант кафедры общего и сравнительного языкознания, Московский государственный лингвистический университет, ул. Остоженка, 38, стр. 1, 119034 г. Москва, Россия, chlopova_anna@mail.ru, https://orcid.org/0000-0002-6576-4111 